\title{
Development of Customized Bank Software and Survey on Customized Design Phase Issues on BMS
}

\author{
S. Prabu \\ School of Computing Science \& \\ Engineering \\ Vellore Institute of Technology \\ Vellore, Tamilnadu, India
}

\author{
Aman Sharma \\ School of Computing Science \& \\ Engineering \\ Vellore Institute of Technology \\ Vellore, Tamilnadu, India
}

\author{
Swarnalatha. P \\ School of Computing Science \& \\ Engineering \\ Vellore Institute of Technology \\ Vellore, Tamilnadu, India
}

\begin{abstract}
The paper gives the concept to design software for banking system and also provides information about how to solve problem which generally comes the banks. Banking Systems play a major role for helping customer information. It could be traditional bank system or a live bank system. The paper derives indicators of the login security and structure of banking system. We use tools which estimate bank transaction. A Live Banking System which mainly reduces the manual work and time. The system facilitates the Bank Manager to view all the customer information and the customer can view only personal amount information. It also facilitates to access account details, updations, etc., They are meant for the purpose of impacting knowledge and forming an excellent set of banking tools that are developed which can generate individual accounts. Banking System that is used in storage and administration save a lot of money and time in opening and updating the accounts but generally fail in security. In the paper we would be discussing various concepts for developing banking system that in turn provide us with a way of creating, searching and updating account customer details. EXE (Banking system editor) and other tools such as security system that would be used with the help of Security Management System (SMS). The paper titled Bank Management System (BMS) software deals with managing the bank accounts activities in an efficient manner and is developed in Visual Basic which mainly focuses on basic operations in a bank like adding customer information, deleting customer information, updating customer searching, customer information and also maintain the transactions.
\end{abstract}

\section{Keywords}

Bank System, Customer, Design Issues

\section{INTRODUCTION}

Banking system always views at latest ways to meet the customer requirements in an effective, more convenient, and efficient manner. In case of payment system and money creation process, banks play a major role. Moreover, bank credit is an important factor of investment money and growth. Today computerized banking system play a significant role to solve customer problems easily as well as to create an excellent relationship between bank and customer which is helpful to increase number of customers for bank that provides excellent facilities with reduction of paper work. The paper provides details about the entire software requirements specification for the Banking System and also gives features and bank architecture. All the information of all Bank Customers will be maintained and various searching options will be available to keep a follow and get information. Also it takes care of Banking Report of various customers. There will be search option available if the operator needs to find a particular customer. According to the paper software works relatively as efficient as other packages related to the Banking System.[2][11][9] It uses simple database rather than complex ones with high requirements and it provides good and easy graphical user interface to both Bank and Customer. The Banking System software provides good graphical interface for the front end of the database and a good informative interface for the rear end. In the paper, Banking System focuses mainly to reduce the manual work and time. The system provides Bank Manager to view all the customer information and the customers can view only their transactions. It also gives access to account details to retrieve information and update the account details and other transactions as well. Traditional Banking System was different from this Banking System by way of reducing the paper work that was tedious and also everything was dependent on the manual work. Online Bank System is userfriendly where customer can do transactions easily by reduction of manual wok. System can perform excellent operations for customers with user-friendly environment.[11][9] Online Banking System perform operations like Debit the transaction, Credit the transaction, find customer information and update the account information. For European countries we assess the impotence of online transaction as compared to domestic bank spillovers compared to the result of our system which gives the system same as abroad banking system which in currently following Indian banks. The reason is because of easy satisfaction of all customer requirements and displays an interacting platform. As per a high-speed internet infrastructure has been developed and people used to it, the financial tasks have also been engaged in internet field.

\section{PROBLEMS IN TRADITIONAL BANKING SYSTEM}

Traditional banks provide direct interaction between customer and bank representative wherein the interaction comes under person to person communication or direct bank communication. But still more problems comes in traditional banking system.[2]

\subsection{Based on Manual work}

Traditional bank systems were not good because they were based on manual work which takes too much of time due to the system problems like stand in queue, fill the form and waiting problems. [11][9]

\subsection{Inconvenient locations}

Banks were located in different locations that were too far from their residences or offices. In the situation travelling problem and wasting time has become the major issue.[5] 


\subsection{Fixed Schedules and time limitation}

In bank fixed time for close bank and time limitation for each customer will be taken into account. Within the time, work has to be finished.[5]

\subsection{Less Security}

In traditional bank system, unauthorized person can access the data without permission. Security was the major problem in traditional bank system. [5]

\section{DESIGN ISSUES FOR COMPUTERIZED BANKING SYSTEM}

\subsection{Online money transfer facility}

In Computerized banking system where online money transfer facility is major concern. According to the facility customer can transfer money from one account to another account easily.[5]

\subsection{Online Mobile recharge facility}

In this facility, customer can recharge mobile through online recharge which consumes the time.[3]

\subsection{View Transaction}

Customer can view transaction at any time and also performs online record which can be the major concern for a business man.[3]

\subsection{Update Bank customer information}

Bank manger can update customer information according to customers.[3]

\subsection{Powerful Security System}

Unauthorized person cannot access customer's information without the permission of the database administrator.[4]

\subsection{Easily account maintenance}

Account maintenance can be easily compared to traditional bank system who can update the information into the database.[4][7]

\subsection{Online lost cards report}

In this facility, customer can give online card lost report where in the bank will dispatch cards to customer homes.[8]

\subsection{Pay credits bills online}

According to the facility of pay credits bills online, customer can pay water, electricity and other bills online.[13]

\subsection{4 hours facility available}

In the 24 hours facility available, the public can access facility at any time with no any retraction may be involved to access money.[13]

\subsection{ATM machine for access cash}

ATM machine may be helpful for bank customers to access cash at any time.[14]

\section{RELATED WORK}

Our proposed system performs operation like customer relationship manager, accounting general ledger, payments, withdraw, store information into database and provides proper security platform to customers.[12][6] It can work on internet and through call centers, customer can check the account and block the cards also. System gives some of the advantages like fully integrated, nonstop banking, real time transactions and maintains relationship between the customer and the bank representatives. System also maintain customer information as well as it provides a customer, an efficient path. System also been responsible for entire bank management process including customer information which gives an excellent customer relationship platform. The research paper also helpful to develop bank software and gives design reasons for developing online Bank Management System(BMS)[1][15]. Bank management systems gives facilities like Online lost cards report, Security, View Transaction, Online money transfer facility, etc,. Our system provides benefits of good quality working PC with all the requirements as stated in the hardware interfaces, Works for medium size information databases and also not should not be overloaded.[10]. The software is totally public contained and works relatively as efficient as other packages related to the Banking System. It uses simple database rather than complex ones for high requirements and it provides good and easy graphical user interface to both Banks and Customers. Login to the system through the first page of the application ability to print the Report based on a specific design, Login page should have proper authentication mechanism. Database should maintain all customer records, gives the User or Manager, the password, updations related to the table field (Customer name, Address, Debit amount, Credit amount etc), View the information of all the Banks and Customers in result interface, to view transactions, to protect the public online. 


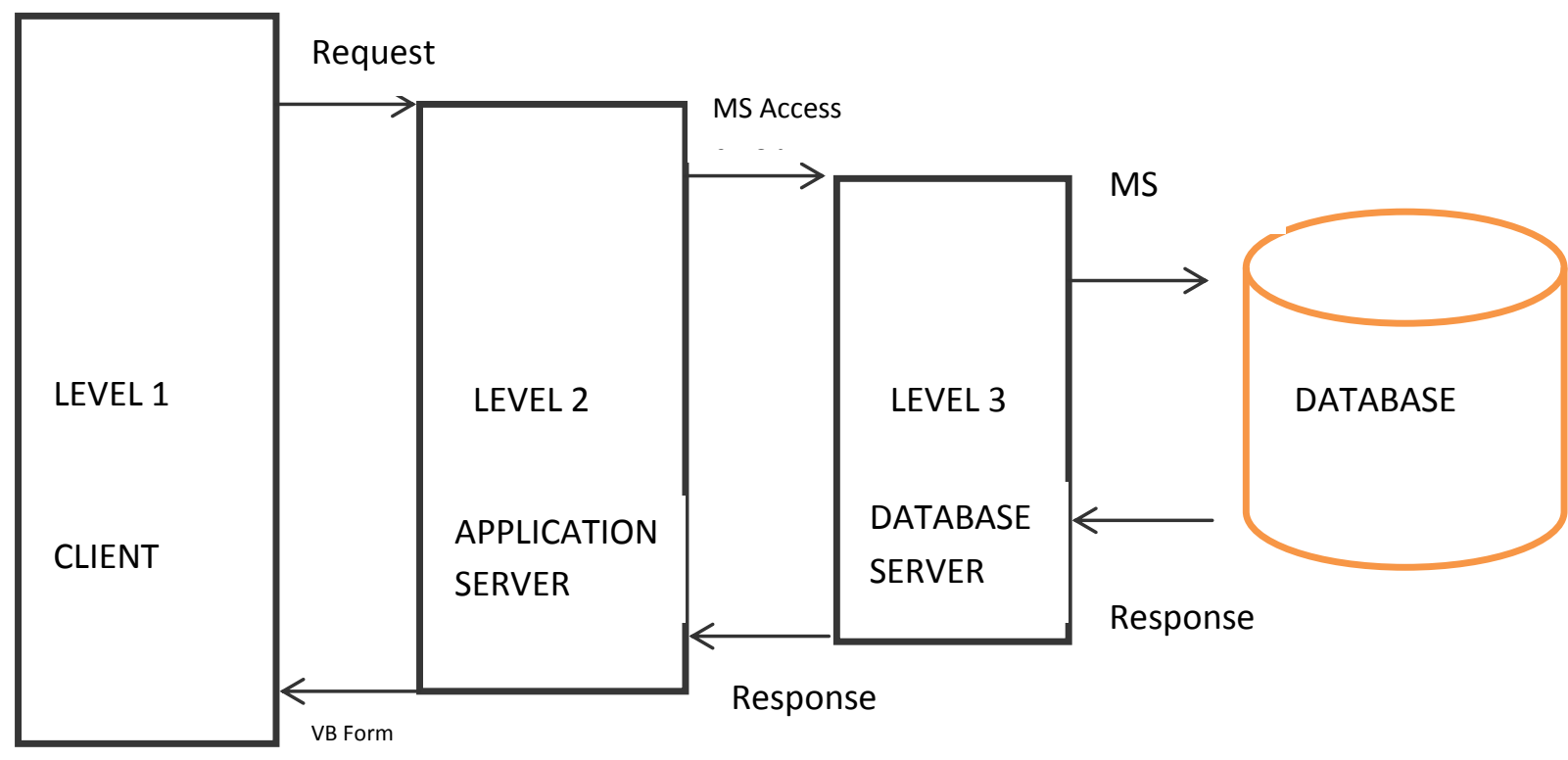

CLIENT-SERVER ARCHITECTURE

Fig 1: BMS system Design \& Working

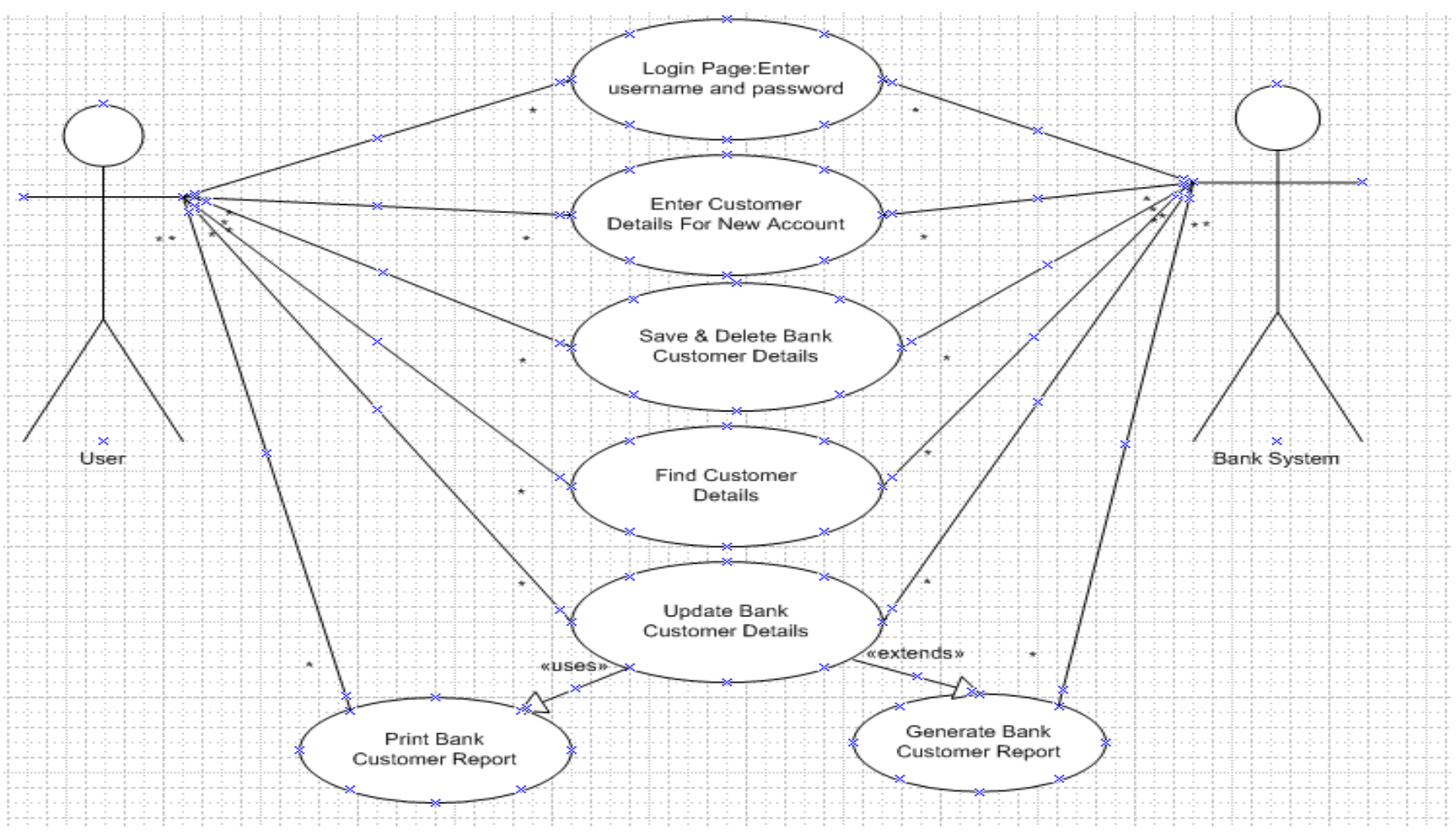

Fig 2: Use Case Diagram BMS system Design \& Working 


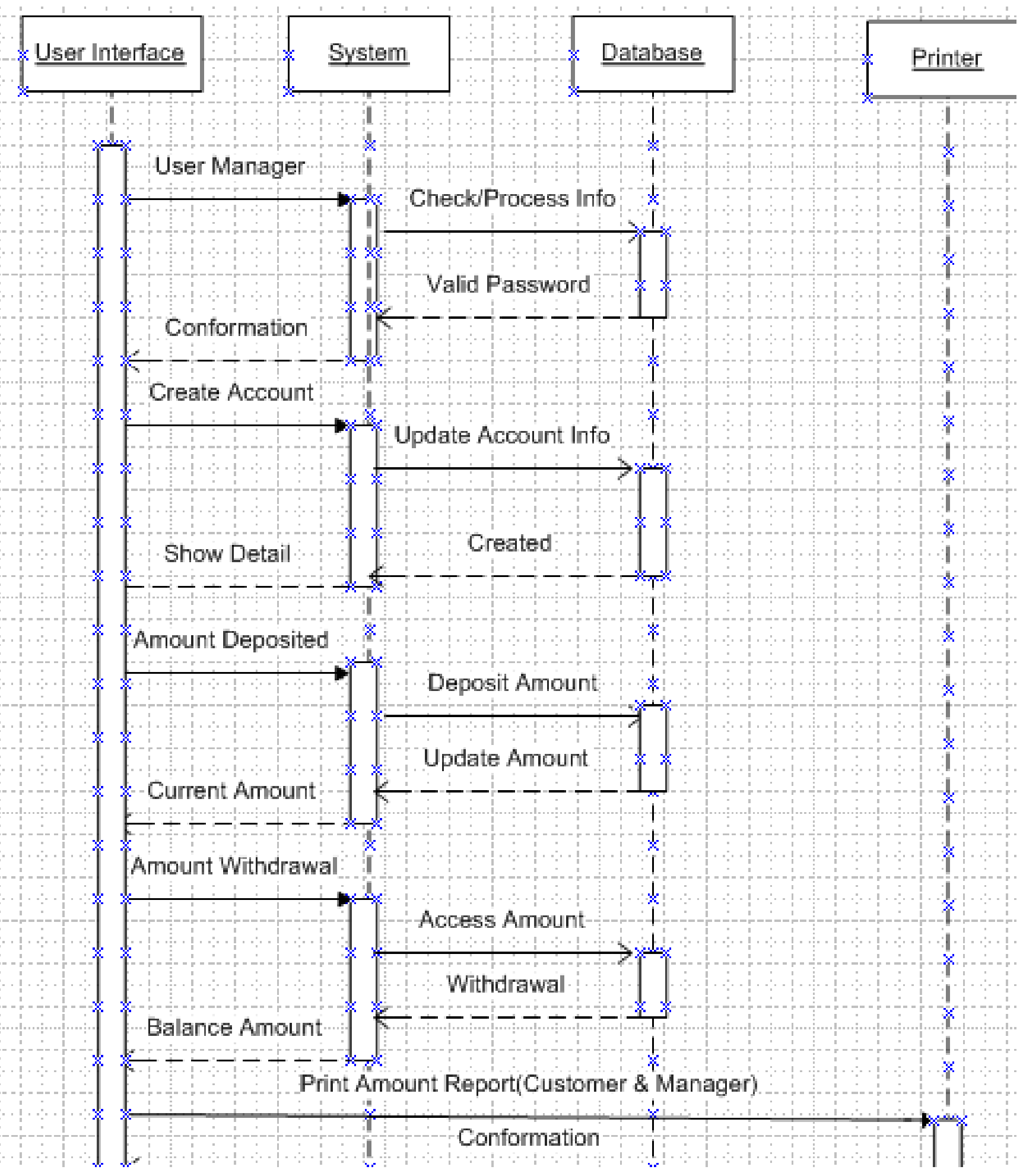

Fig 3: Sequence Diagram BMS system Design \& Working 


\section{SNAPSHOT}

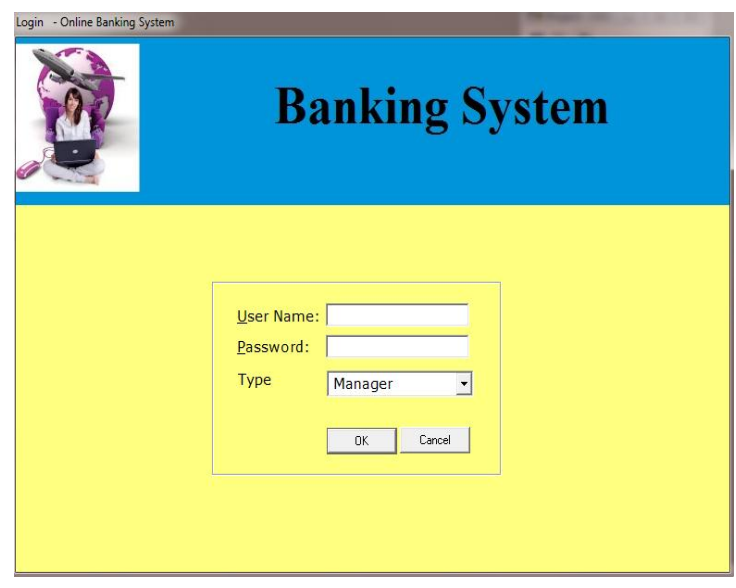

(a)Login Page

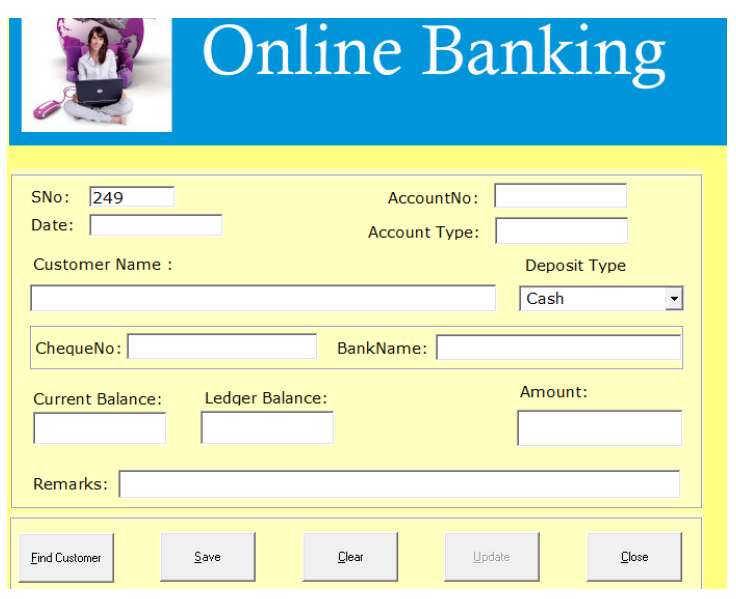

(C)Balance Enquriy
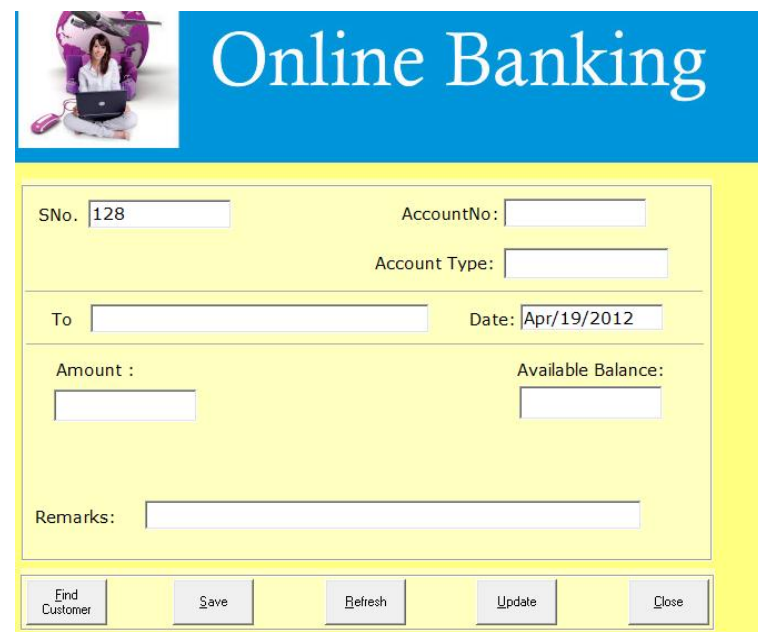

(e)Balance Amount

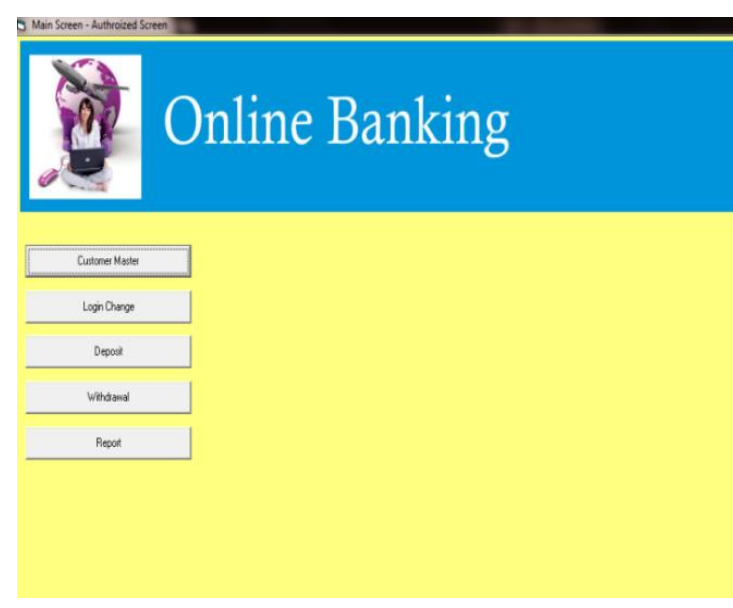

(b) Customer Master

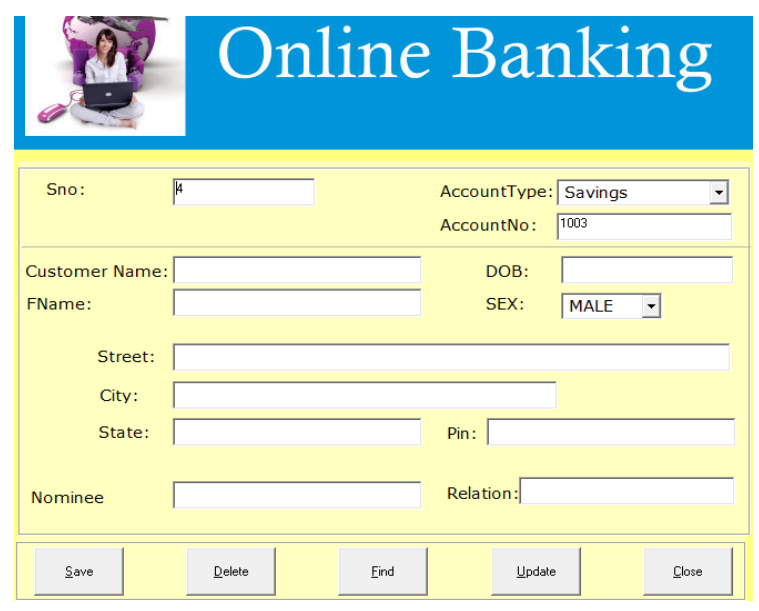

(d)Customer Information
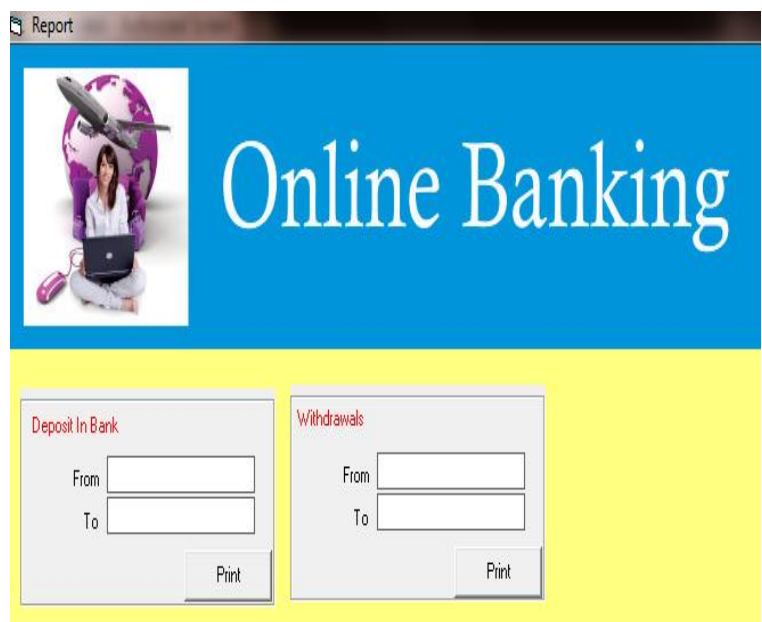

(f) Customer Report 


\section{CONCLUSION}

According to the paper, bank system performs major task for improving banking system factor and adding some new trends which can be helpful to maintain customer relationship platform and play a major role in research. In the paper created, banking system is a major research issue, which will be helpful to solving banking issues as well as consuming and reducing manual work. The paper also fit into a business man who would like to start a new bank to a structure of online banking system. Banking is becoming much more common. Customer can pay your bills online and access a record of your checking account transactions online. Banking is a great feature, and most banks do offer it. Banking makes everything you do with your finances a bit easier. Customers can access the information anywhere that has access to the Internet. It makes your financial life much easier to manage the transactions.

\section{REFERENCES}

[1] F.I. Anyasi and P.A. Otubu, "Mobile Phone Technology in Banking System: Its Economic Effect", Patrick Honohan. Research Journal of Information Technology 1(1): 1-5, 2009.

[2] Fengling Han, Jaiankun Hu, Xinhuo Yu, Young Feng, Jie Zhou,"A novel hybrid crypto-biometric authentication scheme for ATM based banking applications", D. Zhang and A.K. Jain (Eds.): ICB 2006, LNCS 3832, pp. 671- 681, 2005.@ Springer-Verlag Berlin Heidelberg 2005

[3] Halimah, B. Z., Azlina, A., Sembok, T. M., Suffian, I., Azman, M. N. S., Azuraliza, A. B., Zulaiha, A. O., Nazlia, O., Salwani, A., Sanep, A., Hailani, M. T., Zaher, M. Z., Azizah, J., Norfaezah, M. Y., Choo, W. O., Abdullah, C., and Sopian, B., "Evaluation of HiCORE: Multitiered Holistic Islamic Banking System based on User Acceptance Test," in Information Technology (ITSim), pp. 1-6,2010 International Symposium in, 2010.

[4] Jacky MallettIcelandic Institute of Intelligent Machines Reykjavik University Reykjavik, Iceland,"A System Analysis of the Basel Capital Accord's Regulatory Control over the Behaviour of Modern Banking Systems", Proceedings of IEEE Conference, ISBN: 9781-4673-0750-5/12, 2012.

[5] Jie Zhou, Member, IEEE, and Jinwei Gu, "A modelbased method for the computation of fingerprints' orientation field", IEEE Transactions On Image Processing, pp.1-16,2002

[6] Jifang An, Jianhua Sun, "An Application Of Banking Business Automatic Monitoring System Based On AIX
Platform", Ninth International Symposium on Distributed Computing and Applications to Business, Engineering and Science, Hong Kong, China ISBN: 9780-7695-4110-5, August 2010.

[7] Khalid Saeed, Atsushi Fukuda," Testing Design of a Social Innovation The Environmental Mitigation Banking System", Proceedings of the 36th Hawaii International Conference on System Science, Track 3Volume 3, Page 92.2, ISBN: 0-7695-1874-5,IEEE Computer Society,2003.

[8] Mo Yufeng, Lin Qingxia, "A Self-Service Banking System Based on Subsumption Architecture", proceedings of the $2^{\text {nd }}$ IEEE International Conference on Information Management and Engineering,page(s):564 567 ISBN: 978-1-4244-5265-1/10, 2010.

[9] Ratha, N.K, Karu, K. Chen, S., Jain, "A real-time matching system for large finger print databases", IEEE Trans. on Pattern Anal. Machine Intel., Vol. 18,No.8, 1996.

[10] Thomas E. Grebe, "Application of Distribution System Capacitor Banks and Their Impact on Power Quality", IEEE Transaction on industry application vol. 32, No 3 May/July 1996.

[11] Umut Uludag, Sharath pankanti, Salil Prabhakar, Anil k Jain, Biometric cryptosystems: Issue and challenges", and A.K".Jain, Proceedings of the IEEE, vol.92, no.6, pp.948-960, 2004.

[12] Vibha Batra, Karthik Srinivasan, Puneet Maheshwari, "Indian Banking Sector: Challenges unlikely to derail the progress made", The Securitisation and Reconstruction of Financial Assets and Enforcement of Security Interest Act, $2002 . \quad$ Website: http://www.icra.in/Files/ticker/Banking\%20notefinal.pdf

[13] Yuan Fang-ying, The Credit Risk Macro Stress Testing of the Chinese banking system, Proceedings of Chinese Control and Decision Conference (CCDC),ISBN: 978-14244-8738-7/11, 2011.

[14] "Automated phone system and Online Banking Information", State Farm Bank, F.S.B, Bloomington, IL FSB-51302.Website: http://www.statefarm.com/bankupdate/bankupdate.pdf

[15] "Swiss Banking", Swiss Bankers Association, PO Box 41824002 Basel, Switzerland, Compendium,page nos.188 .

2010 